ISBN-978-93-86878-24-3

14th LISBON International Conference on Agricultural, Biological, Environmental and Medical

Sciences (LABEMS-18)

Lisbon (Portugal) Dec. 17-19, 2018

\title{
Effects of Low Temperature on Concentrations of Soluble Sugars and Quercitol of Cork Oak Seedlings
}

\author{
Rached-Kanouni Malika ${ }^{1}$ and Kara Karima ${ }^{2}$ \\ ${ }^{1}$ University Larbi Ben M’Hidi, Oum El Bouaghi, Algeria \\ ${ }^{2}$ University des Frères Mentouri, Department de Biologie et Ecologie Végétale, Constantine, Algeria \\ (Email: kmalikbio@yahoo.fr)
}

\begin{abstract}
Cork oak (Quercus suber L.) forms real cork woods which are playing a central role in the ecological, economical, and social field in Algeria. For several years however, it has undergone a substantial decline. Forester replanting of the cork oak seedlings entails a better apprehension of the response of this plant to the local abiotic constrains. Within this context, this work focuses on the impact of short periods of low temperatures on certain biochemical aspects of the cork oak seedlings. Sowings of cork oak are cultivated in controlled conditions at $20^{\circ} \mathrm{C}$ and a 16-hr photoperiod. We have measured the content soluble sugar (sucrose, glucose, fructose) and the content quercitol in the various organs of these sowings. Four thermal stresses (5, 2, 0 and -2) were applied; the results show that there is a significant increase in the content soluble sugar. High accumulation of sucrose was observed in root and stem, while the rate of hexoses (glucose and fructose) was higher in leaves. Quercitol, an aliphatic polyol, was found to be accumulated in leaves and this accumulation increased as temperatures decreased. Based on our findings, the response of cork oak seedling to low temperatures is likely to be complex and organ-dependent.
\end{abstract}

Keywords: low temperatures, quercitol, Quercus suber, soluble sugar

\section{Introduction}

The cork oak forms real cork woods which play a significant part on the ecological, economical, and social ground in Algeria. This tree is especially known for its industrial value (quality of the wood and the bark), function in the ecosystem, anti-erosive capacity and resistance to fires. In comparison with the other forestry trees, the cork oak has been undergoing, in the last years, important decline with startling proportions in the Western part of the Mediterranean. Most cork communities are old, and repeated uncorking enhances the mortality of the trees [1].

Indeed, Algeria provides 5\% of world production of cork. This formation, despite its value, had known a continued decline and alarming translated by a regression in its surface of 440000 to 229000 hectares currently considered as productive (10\% of the world cover) [2]. This regression is the result of a bad management combined with the climate changes affecting the production of cork and those limiting natural regeneration [3].

Because of their immobility, plants have developed a set of multifactor mechanisms that enable them to perceive and respond specifically to different constrains they are subjected to. Among these are low temperatures which cause the reduction of the enzymatic reaction celerity, the modification of membrane fluidity therefore inducing negative effects on most biological processes.

To give a first insight into the mechanism involved behind the response of cork oak seedlings to short-tem exposure to low temperatures, we were focused on the impact of this abiotic constraint on the evolution of the principal biochemical markers to low temperatures such as soluble sugars (glucose, fructose, sucrose) and 
quercitol in the different organs of the plant. This is for aim of understanding the capacities of adaptation and the tolerance of oak cork at thermal variability (low temperatures).

\section{Materiel and Methods}

Our study was carried out on cork oak seedlings (Quercus suber L.) from acorns collected on adult subjects of the region of the province of Skikda, in a sub-humid ambient weather with soft winter $\left(\mathrm{m}=10.55^{\circ} \mathrm{C}\right.$, $\mathrm{M}=24.25^{\circ} \mathrm{C}$ and $\mathrm{P}$ is $830 \mathrm{~mm}$ ). The site of collection is situated closely at the intersection of parallel $36^{\circ} 37$ of North latitude and of meridian $7^{\circ} 30^{\prime}$ of East longitude at $500 \mathrm{~m}$ high. They were grown in plastic pots of a 50 $\mathrm{cm}$ of size and $60 \mathrm{~cm}$ deep, filled with peat (organic material $2 \%$, dry material $3 \%$, water retention $30 \%, \mathrm{pH}=6.7$ and resistivity $1200 \mathrm{ohm} . \mathrm{cm}$ ).

The cork oak has an endogenous rhythmic growth that is expressed by the development of successive identically structural unities, called waves or flushes. After the end of the second growth wave, the seedlings were subject to the treatment of $3 \mathrm{~h}$ at the following temperatures: $5,2,0,-2$ and $20^{\circ} \mathrm{C}$ (control)..

\subsection{Extraction}

Soluble sugars and quercitol contained in the different organs are extracted by incubation of $20 \mathrm{mg}$ of powder in $1 \mathrm{ml}$ of ethanol at $80 \%$ for 30 minutes followed by a $14000 \mathrm{~g}$ centrifugation for 10 minutes. Three successive extractions are done in varying the ethanol solution used. During the 1st extraction, we use an ethanol solution at $80 \%$ containing mannitol at $0.125 \mathrm{~g} / \mathrm{l}$ which serves as a standard in dosages with HPLC. For the 2nd extraction, we again use ethanol at $80 \%$ but with no mannitol. Next, for the 3rd extraction, ethanol is at $50 \%$ in order to extract the hardly soluble metabolites in alcohol. Columns are prepared by the mains of pipettes ends cut at one end then filled as follows: (polyester fabric rug $+100 \mu l$ Dowex $50+150 \mu \mathrm{AGX}+400 \mu l$ of the active charcoal +100 PVPP). Active charcoal is only used in the event of alcohol extracts obtained from the powders of samples. It is used to eliminate the molecules not retained by PVPP and to clarify the extracts as well. PVPP serves to eliminate the big molecules and polyphenols. In priority, each column is moisturised again with $100 \mu \mathrm{l}$ of ethanol at $80 \%$. Likewise, a slight pressure is applied to enhance the passage of the alcohol extract. The purpose is to trap all the charged molecules. They then let only carbohydrates pass. The alcoholic extracts coming from all the three supernatant are filtered as they are collected. We rinse twice with $1 \mathrm{ml}$ of ethanol at $80 \%$ before putting to dry the solutions therefore obtained with "Speed-vac" over one night. The soluble sugars and the quercitol are quantified with the HPLC.

\subsection{Statistical Analysis}

Results gotten of the studied parameters soluble sugars (sucrose, fructose and glucose) and quercitol have been interpreted statistically by the ANOVA to a factor by means of the analysis of the variance, while using the software Excel Stat (2009).

\section{Results and discussion}

The results described in Figure 1 show that the lowest sucrose content was found in the leaves, in comparison with stems and roots. In leaves, a slight accumulation of sucrose was observed in the control seedling and seedlings kept at $-2^{\circ} \mathrm{C}$. In the stems, the sucrose content increased slightly at temperatures $5^{\circ} \mathrm{C}$ (26\%) and decreased at $-2^{\circ} \mathrm{C}$ and $0^{\circ} \mathrm{C}(44 \%$ to $49 \%)$. The root sucrose content was similar to that of the control sample up to a thermal level of $2^{\circ} \mathrm{C}$ and then decreased from $0^{\circ} \mathrm{C}(28 \%)$. The lowest level was observed at $-2^{\circ} \mathrm{C}$ (a reduction of $52 \%$ in comparison to the control seedling). 


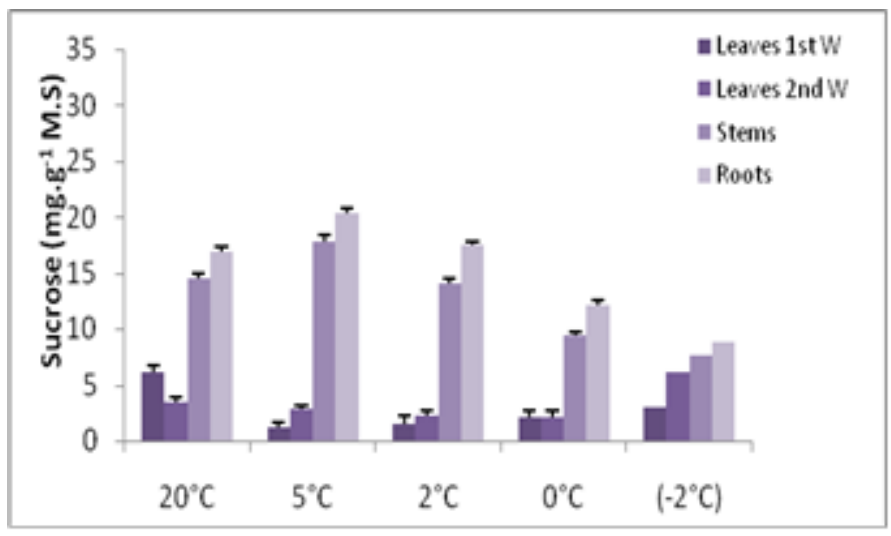

Fig. 1. Sucrose content in the different organs of cork oak seedlings.

Unlike sucrose, the highest glucose content was obtained in leaves of the $1^{\text {st }}$ growth wave (Fig. 2). For the leaves submitted to low temperatures, the results at $5^{\circ} \mathrm{C}$ and $2^{\circ} \mathrm{C}$ were increasing to those of the control whereas a reduction of $24 \%$ was noted at 0 and $-2^{\circ} \mathrm{C}$. In stems, there was no difference between $0{ }^{\circ} \mathrm{C}$ and $-2^{\circ} \mathrm{C}$ although increase at $2^{\circ} \mathrm{C}$ and $5^{\circ} \mathrm{C}$ were observe $(91 \%)$. As in the roots, the reduction in glucose at the different temperatures was $41 \%$ at $5^{\circ} \mathrm{C}$ and was more significant from $-2^{\circ} \mathrm{C}$.

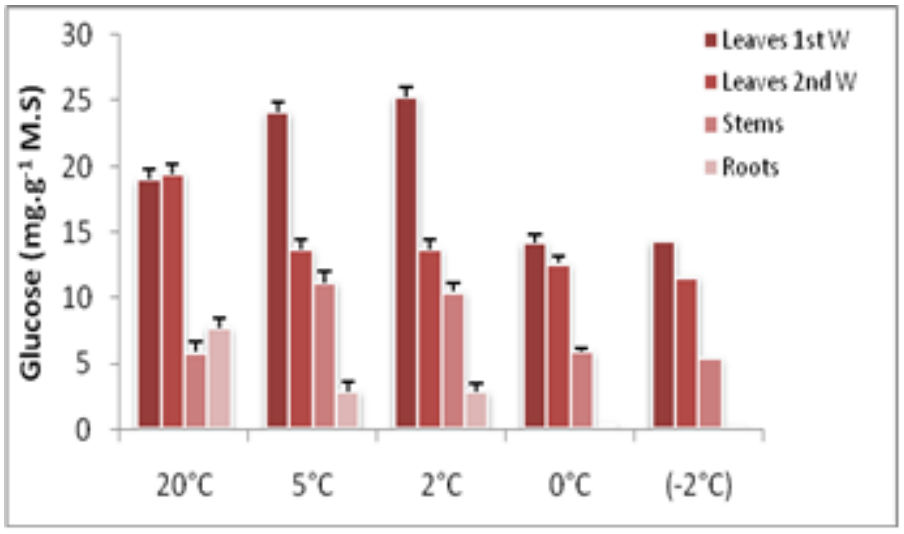

Fig. 2. Glucose content in the different organs of cork oak seedlings

Like glucose, quantities of fructose were higher in the leaves than the other organs (Fig. 3). These quantities decreased when the leaves were submitted to low temperatures, with a very low level at $-2^{\circ} \mathrm{C}$. On the other hand, stems kept at $5^{\circ} \mathrm{C}$ and $2{ }^{\circ} \mathrm{C}$ contained more fructose and were respectively $(70-53 \%)$ whereas those at $-2^{\circ} \mathrm{C}$ revealed a reduction in their content, compared with the control (42\%). In the roots, an increase in fructose content was observed at $2^{\circ} \mathrm{C}$ and $-2^{\circ} \mathrm{C}$ in relation to the control (about 100-300\%). In higher plants, sucrose synthesized in the chlorophyllian organ cytoplasm accumulates during the vegetative phase in perennial tissues and especially in the reserve parenchyma of the branches and roots [4]. Sucrose which is the main form of sugar transport in plants is of additional importance in the physiology of the plant. Likewise, its role in the response to the cold has been extensively argued and different functions such as the cryoprotection of proteins and membranes and the maintenance of osmolarity was attributed to this soluble sugar [5]. In Arabidopsis, sucrose might be involved in the maintenance of photosynthetic activity during exposure to cool temperatures [6]. This lack of sucrose accumulation in the leaves that undergo low temperatures seems to be in contrast with the data of the literature [7]. This is not the case for stems and roots of oak seedlings (Fig. 1) in which sucrose might partly come from the local or distal mobilization of starchy reserves. In the walnut, this mobilization has been described within the context of the repair of the winter embolism of xylem vessels. Even though hexoses also contribute in tolerance to the cold weather in the different tissues [8], we cannot infer that the mechanism of tolerance of the cork oak seedling leaves to low temperatures would mainly be based on an accumulation of 
these soluble sugars. This shows that the specific role of a compound in the tolerance of plants to the cold is very unlikely. Likewise, some recent studies suggest that soluble sugars in combination with proline could preserve the integrity of the membranes in plants exposed to freezing temperatures.

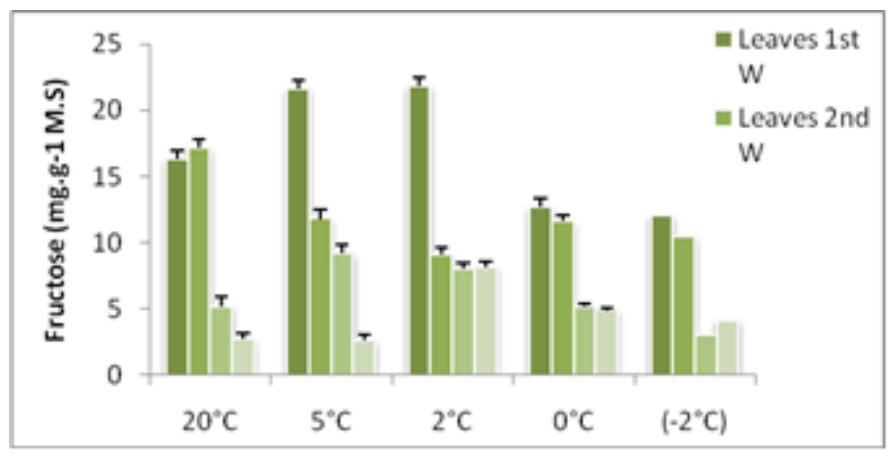

Fig. 3. Fructose content in the different organs of cork oak seedlings

As regards quercitol, increase rates in the different organs were proportional to the intensity of cold, more particularly for the leaves (Fig. 4). Variations of quercitol in leaves of the 2nd wave of growth were more considerable than those observed at leaves of the 1 st wave of growth. They ranged from $214 \%$ at $5{ }^{\circ} \mathrm{C}$ to $253 \%$ at $-2^{\circ} \mathrm{C}$. The quercitol content of the stems for the different treatments displayed two distinct phases of accumulation: the first phase ranged from 5 to $0^{\circ} \mathrm{C}$ where this content was of about $78 \%$ in relation to the control; the second phase corresponded to $-2^{\circ} \mathrm{C}$ with increase in percentages of more than $228 \%$. In the roots, and in relation to the control, the quercitol content increased from $5^{\circ} \mathrm{C}(653 \%)$ to $-2^{\circ} \mathrm{C}(744 \%)$. In fact, although quercitol content markedly increases in the stems and roots since the application of $5^{\circ} \mathrm{C}$, this increase is even greater in the leaves, as those of wave 2 . These results show that among the measured out soluble molecules (sucrose, hexoses and quercitol) in this study, quercitol may play a leading part in the response of the cork oak seedling leaves to short-term exposure to low temperatures.

The application of the thermal conditions leads to an accumulation of quercitol in foliar tissues of eucalyptus [9]. Passarinho \& al. showed that the transcription of the inositol Omethyltransferase gene involved in quercitol production is induced by low temperature [10].

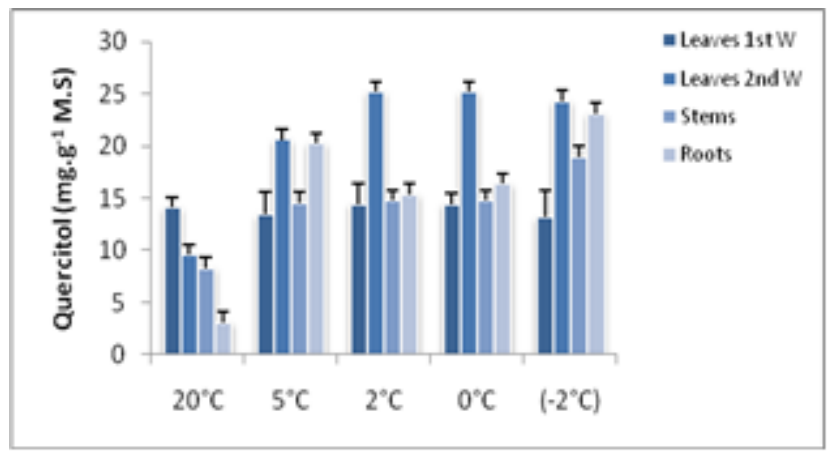

Fig. 4. Quercitol content in the different organs of cork oak seedlings

\section{Conclusion}

Changes in the chemical composition of the leaves, stems and roots of $Q$. suber seedlings transferred in low temperatures can have serious implications for their capacity of adaptation to climatic change. Therefore, the substantial concentrations of quercitol in stems and roots and fructose in the leaves of $Q$. suber could be biochemical markers for its adaptation to the cold. 


\section{References}

[1] M. Bakry, M. Abourouh,, "Nouvelles données sur le dépérissement du Chêne-liège (Quercus suber L.) au Maroc". Ann. Rech. For. Maroc, 29, 1996, pp. 24-39.

[2] B. Belghazi, M. Ezzahiri, M. Qarro, M., Sabir, "Bilan de sept années de culture sur la régénération naturelle du Chêneliège au Moyen Atlas oriental (Bab Azhar) ". Ann. Rech. For. Maroc. Actes de l'atelier sur le sylvo-pastoralisme, E.N.F.I., Salé (Maroc), 1995, pp.25-28.

[3] D. Côme, "Les végétaux et le froid". Edit. Hermann, Editeurs des Sciences et des Arts (Paris), 1992, 599p.

[4] S. Yamaki, "Distribution of sorbitol, neutral sugars, free amino acids, malic acid and some hydraulic enzymes in vacuoles of apple cotyledons". Plant Cell Physiol, 23, 1992, pp. 881- 889.

[5] M.Yuanyuan, Z. Yali, L.S. Hongbo, "Roles of plant soluble sugars and their responses to plant cold stress". African Journal of Biotechnology, 8 (10), 2009, pp. 2004-2010.

[6] I. Ensminger, F. Buscha, N.P.A. Huner, "Photostasis and cold acclimation: sensing low temperature through photosynthesis". Physiologia Plantarum, 126, 2006, pp. 28-44.

https://doi.org/10.1111/j.1399-3054.2006.00627.x

[7] V. Hurry, A. Strand, R. Furbank, M. Stitt, "The role of inorganic phosphate in the development of freezing tolerance and the acclimatization of photosynthesis to low temperature is revealed by the pho mutants of Arabidopsis thaliana". The Plant J. 24(3), 2000, pp. 383-396. https://doi.org/10.1046/j.1365-313x.2000.00888.x

[8] A. Sakai, W. Larcher, "Frost survival of plants-Responses and Adaptation to Freezing Stress". Ecol. Studies 62, SpringVerlag (eds), 1997, pp. 112-133.

[9] A. Merchant, P.Y. Ladiges, "Quercitols links the physiology, taxonomy and evolution of 279 eucalypt species". Global Ecology and Biogeography, 16, 2007, pp. 810-819. https://doi.org/10.1111/j.1466-8238.2007.00338.x

[10] J.A.P Passarinho, P. Lamosa, J.P. Baeta, H. Santos, C.P.P. Ricardo, "Annual changes in the concentration of minerals and organic compounds of Quercus suber leaves". Physiologia Plantarum 127, 2006, pp. 100-110 https://doi.org/10.1111/j.1399-3054.2006.00655.x 